To cite as: Kim, J, Saidani, M, \& Kim, HM. "Optimal Product Family Architecture Design and Commonality Decision for Sustainability and Intellectual Property Protection." Proceedings of the ASME 2020 International Design Engineering Technical Conferences and Computers and Information in Engineering Conference. Volume 11B: 46th Design Automation Conference (DAC). Virtual, Online. August 17-19, 2020. V11BT11A034. ASME. https://doi.org/10.1115/DETC2020-22488

\title{
IDETC2020-22488
}

\section{OPTIMAL PRODUCT FAMILY ARCHITECTURE DESIGN AND COMMONALITY DECISION FOR SUSTAINABILITY AND INTELLECTUAL PROPERTY PROTECTION}

\author{
Jinju Kim, Michael Saidani, Harrison M. Kim \\ Enterprise Systems Optimization Laboratory \\ Department of Industrial and Enterprise Systems Engineering \\ University of Illinois at Urbana-Champaign \\ Urbana, Illinois 61801 \\ Email: \{jkim702, msaidani, hmkim\}@illinois.edu
}

\begin{abstract}
With the rapid development of new technology and the growing global competition in industry, it is essential for companies to protect their sensitive product designs and technologies. To ensure that their systems are not exploited by third-party competitors or remanufacturers, original equipment manufacturers often apply physical attributes and/or reduce commonality within a product family to prevent easy reusing and recovering. Yet, these design strategies are key barriers to the sustainable recovery and recycling of products. To address these trade-offs, this paper proposes a stepwise methodology to identify the sustainable optimal product family architecture design while protecting intellectual property on sensitive parts or modules. The developed approach notably allows the selection of suitable and sustainable candidates to share among products, taking into account the cost-benefit of commonality within the product family. As such, it can be used as a decision support tool to help product designers identify appropriate product family architecture design and find candidates that can be shared within a product family by considering both sustainability and security parameters.
\end{abstract}

\section{INTRODUCTION}

As technology advances and global industrial competition intensifies, it is becoming increasingly important for original equipment manufacturers (OEMs) to prevent leaks of designs and technologies that drive their distinctive features and profitability from potential users or undesirable agents. Besides, for products targeting aftermarket (e.g., printer cartridges, automobile), parts with high resale rates or high profits should be prevented from being recycled and resold by third-party remanufacturers. In this context, protecting intellectual property (e.g., sensitive components and technologies) is becoming an important challenge for OEMs. Intellectual property (IP) encompasses a set of rights that protects applications of ideas and information that have commercial value [1]. IP is a broad concept involving many types of intellectual property rights such as design patents, trademarks, copyrighted material, etc. In our context, for simplicity, IP refers to a set of components that contain important information (or technologies) and/or high potential values that can be utilized in the future.

To prevent third-parties from utilizing their critical designs and components, some OEMs use specific design strategies to protect their IP rather than designing for sustainability. For instance, OEMs can use physical attributes that make it difficult (or impossible) to disassemble and reassemble their products to prevent them from being reused [2]. For product family designs, divergent commonality strategies that do not share sensitive components are used to decrease the efficiency of reuse [3-5]. Unfortunately, these design strategies are in contradiction with sustainable design principles. These strategies usually lead to an ineffective recovery as well as a single use of the product, re- 
sulting in a waste of resources and energy. To tackle this issue, the optimization of product family architecture design with the simultaneous consideration of IP and sustainability is key. Integrating both protection on sensitive components and sustainability in product design presents an important challenge for industries that are willing to adopt a sustainable and secure approach in new product development.

The paper proposes a novel methodology, including an optimization model to identify sustainable product family architecture design while protecting their security (i.e., IP related parts and/or modules) based on matrix-based tools. The pro- posed step-by-step approach aims to orient towards the selec- tion of suitable and sustainable parts and/or modules that canbe shared among products considering the cost-benefit of com- monality within the product family in the context of product se-curity and sustainability. The rest of the paper is organized as follows. Section 2 reviews relevant prior work/literature on this topic. Section 3 depicts a mathematical model for sustainable product architecture design and selecting shared modules while considering IP protection. Section 4 illustrates the optimization model through a case study on printers. Finally, conclusions and future research are discussed in section 5 .

\section{LITERATURE REVIEW}

Product architecture can be defined as a "comprehensive representations of a set of characteristics, such as the number and type of components, the number of interfaces between components, and the fundamental structure of the product" [6,7]. The architecture of a product is important not only in the optimal design of individual products but also in the process of determining shared components (or modules) between product variants within a product family $[3,8,9]$. This section explores the contributions and limitations of previous studies on product architecture design and commonality decisions, particularly through the lens of product security and sustainability.

\subsection{Modular Design Strategies in a Context of Prod- uct Security and Sustainability}

In a context of increasing regulations to tackle global warming (mitigation of carbon dioxide emissions), optimal modulebased product configuration appears as a relevant to support manufacturers in reducing the carbon footprint of their products while maintaining an appealing range of products for different customer categories. Yang et al. [10] proposed a module-based product configuration method by considering both economical and carbon emission-related environmental impacts in product design and manufacturing. In their study, the product configuration problem was formulated as a mixed-integer programming problem with carbon emission constraints, and a genetic algorithm is used to solve it. Interestingly, their numerical results have shown that such an approach can provide effective decision support for low-carbon and modular manufacturing. Kim and Moon [7] also developed a methodology to identify an "ecomodular" architecture by proposing sustainable modular drivers. However, these studies do not integrate the aspect of IP on sensitive/secured components when defining the appropriate modules.

Henkel and Marco [4] introduced the concept of IP modularity, which aims to protect and capture value in an open innovation model based on real design cases. According to this study, the architecture of IP modularity refers to a module boundary (i.e., IP incompatibility) in different IP status that corresponds to the technical boundary of the module. In many cases of reality, however, the IP-related core elements of the product are highly interconnected with the rest of the system, making it difficult to encapsulate them completely in a module [3,11]. Rojas and Kim [3] also used the concept of modularity for IP protection. Their model applied security-related penalty costs for optimal product design so that components related to sensitive informa- tion are in the same module. However, these studies only consid-ered product design for protecting IP and not sustainability.

\subsection{Product Family Design Strategies in a Context of Product Security and Sustainability}

The identification and specification of suitable product family platforms through modular product design can provide substantial benefits for producers, such as to: increase manufacturing and remanufacturing efficiency and effectiveness, reduce inventory cost, save distribution time, and satisfy the demand for mass customization [12-15]. While some researchers proposed methodologies to address the simultaneous consideration of new and remanufactured products in product family design [16, 17], previous studies of sustainable product family design generally assumed that products within the product family have the same product architecture. Even though the product family performs similar or identical functions, it often uses completely different components or architectures. Nonetheless, such studies consider sustainability in product family design but do not incorporate protecting security.

To bridge part of this gap, Rojas and Kim [3] assumed that products could have different architectures within the product family and proposed a methodology to identify an optimal product architecture and component sharing decisions amongst product family with security consideration. For IP related parts, it is assumed that they are in a proper module and that this module could not be shared amongst the product family. However, this study only considered the difficulty of redesigning the product family to determine commonality, but not the economic value or ecological benefits that could arise when shared. All in all, in the present literature, there is still a lack of integrated studies related to sustainable product family architecture design and protect IP. 


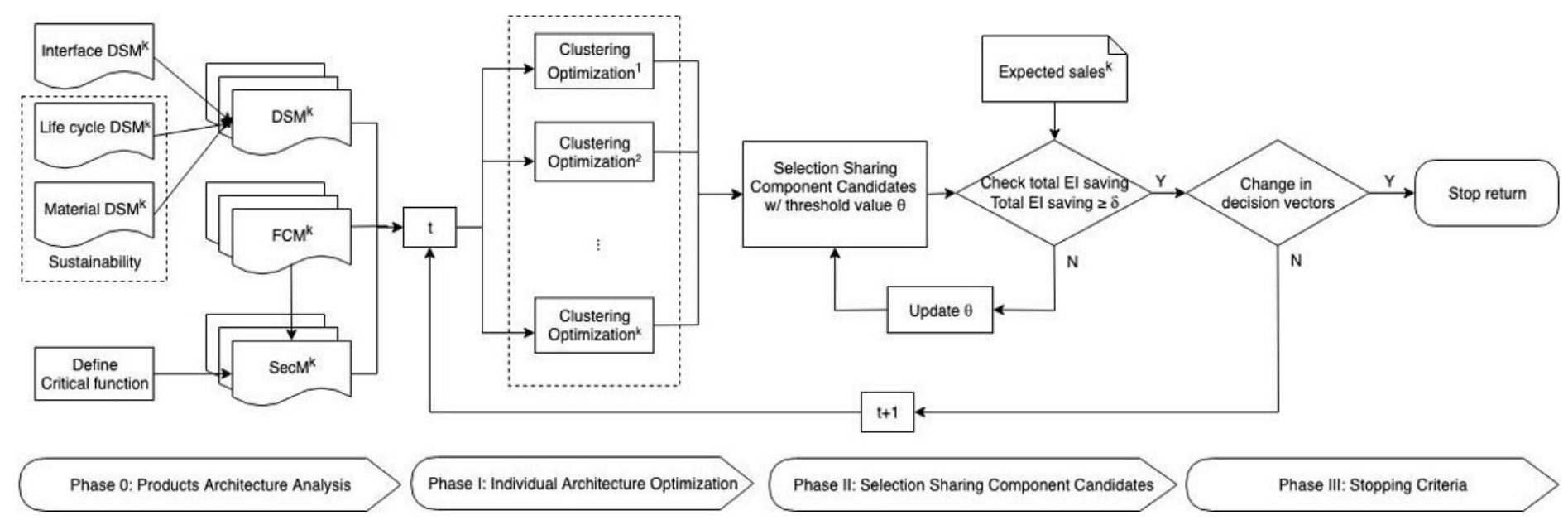

FIGURE 1. Schematic overview of the proposed methodology

\section{MATHEMATICAL MODEL}

The purpose of this paper is to identify the optimal prod- uct family architecture design that considers sustainability while protecting IP-related components and to select candidates that can be shared in consideration of the cost-benefit (potential residual value) of commonality within the product family. The study is particularly intended for OEMs who want to redesign a previously designed product family into sustainable designs while protecting sensitive components from third-parties.

\subsection{Problem Statement}

The developed methodology is built upon the prior relevant framework and studies focusing independently on sustainable design, design for IP protection, and commonality decisions (see, for example, $[3,7,8])$. The workflow of the proposed methodol- ogy is shown in Fig.1. In phase 0, the current product architec- ture design of the product family is analyzed, and the required data are collected and filled out in design structure and functioncomponent matrices (DSMs and FCMs), and secured component data associated with critical (sensitive) functions. For DSMs of individual product designs, the information includes not only interaction information between components, but also component lifespan and material types to consider their sustainability performance. Phase I consists of optimizing the architecture of individual products in a way that addresses secured modules separately and concurrently increases the sustainability performance. Phase II selects candidates for modules and/or components to be shared between products, taking into account redesign risks and potential value for future reuse, based on the structure of products acquired in the previous phase. After selecting shared candidates, the environmental impact saving that can be obtained by this sharing strategy is estimated and checked against the target value. Phase III is to verify the termination condition, and once the stopping criteria are satisfied, the return loop is stopped. Finally, appropriate decisions can be made by product designers and engineers about the product family architecture and commonality on new redesigns that would increase the environmental performance, while protecting their sensitive information.

\subsection{Product Architecture Analysis}

This preliminary phase deals with the analysis of the current product family to redesign its product architecture to increase sustainability and secure IP. Product architecture design requires a clear understanding of the types and number of components that constitute the product, as well as the relationships between them. In particular, as opposed to single product design, designing multiple products requires a comprehensive understanding of whether they perform similar functions or differences between products and which components are involved, as well as analyses of individual products. In this study, the following matrix-based tools are used to gather and compute the information collected for the redesigning of the product family architecture.

3.2.1 Design Structure Matrix (DSM) A DSM isa widely acknowledged approach to define suitable clusters of components into modules [18]. While being a practical tool to represent the different interactions of a complex system in a simple, compact, and visual way, DSM also facilitates the improvement of module architecture, specifications, and interfaces. In a conventional component-based (or interaction) DSM, the three following steps are used to construct the DSM: (i) decompose the system into elements, (ii) document the physical interactions between elements, and (iii) analyze potential clustering. As shown in Fig 2, a typical DSM is filled out with binary values, indicating whether a relationship exists or not between components. In addition to these basic relationships, DSM can be built on 
To cite as: Kim, J, Saidani, M, \& Kim, HM. "Optimal Product Family Architecture Design and Commonality Decision for Sustainability and Intellectual Property Protection." Proceedings of the ASME 2020 International Design Engineering Technical Conferences and Computers and Information in Engineering Conference. Volume 11B: 46th Design Automation Conference (DAC). Virtual, Online. August 17-19, 2020. V11BT11A034. ASME. https://doi.org/10.1115/DETC2020-22488

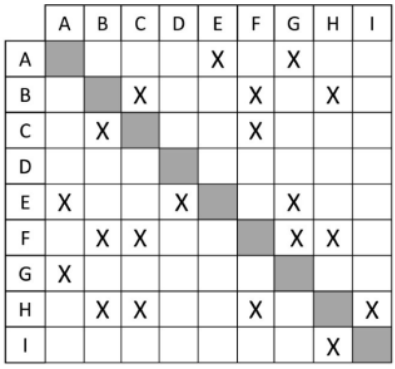

Original DSM

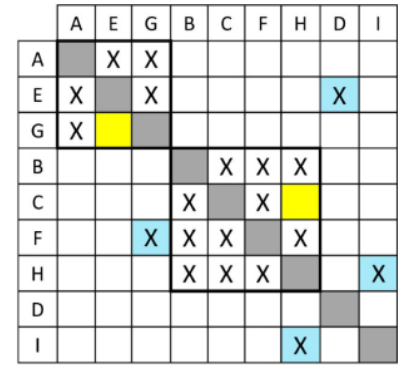

$\mathrm{X}$ Mismatch Type I $\square$ Mismatch Type ॥
FIGURE 2. Unordered and rearranged binary DSMs [8]

other complementary measures such as the characteristics of interfaces, the flow of energy or information, and sustainability aspects to generate modules.

In this study, in addition to the existing interaction between components, sustainability modular drivers (material and lifespan) proposed by Kim and Moon [7] are applied to generate new modules that facilitate their sustainable maintenance and management. Designing product architecture based on similar materials, lifespan, is important for the overall sustainability performance of a product. Modules with similar or compatible materials make recycling easier [19]. Besides, if components within a module have a similar residual lifetime [14], it facilitates maintenance, saves time and effort by not requiring further disassembly operations when replacing the module.

In this study, each DSM cell $(i, j)$ for component interaction $\left(I_{i, j}\right)$, material $\left(M_{i, j}\right)$, and lifespan $\left(L_{i, j}\right)$ is simply created with a value between 0 and 1, based on the following equations (Eq. 1-3). The calculation of lifespan similarity $L_{i, j}$ between components is expressed as a ratio of the minimum and maximum lifespan between components as shown in Eq. (3). If the two components $i, j$ have the same lifespan, the value $L_{i, j}$ is 1 and $L_{i,}$ ${ }_{j}$ becomes smaller if the remaining lifetime difference between components is large.

$$
\begin{aligned}
& I_{i, j}=\begin{array}{ll}
1, & \text { if there are interactions between } i \text { and } j \\
0, & \text { otherwise }
\end{array} \\
& M_{i, j}=\begin{array}{l}
1, \quad \text { if same material is used for } i \text { and } j \\
0.5, \quad \text { if similar material is used } \\
\square 0.3, \quad \text { otherwise }
\end{array} \\
& \begin{array}{r}
L_{i, j}=\min \text { lifespan }(i, j) \\
\max \text { lifespan }(i, j)
\end{array}
\end{aligned}
$$$$
W_{i, j}=\alpha_{1} I_{i, j}+\alpha_{2} M_{i, j}+\alpha_{3} L_{i, j}
$$

The component-based, material-based, and lifespan DSMs are combined through the weighted average method, as shown in Eq. 4.

\subsubsection{Function-Component Matrix (FCM) A} Function-component matrix (FCM) is a representation of the functions and components of a product. It represents the relationship between each function and the parts involved in performing it $[8,20]$. When analyzing multiple products rather than a single product, it is necessary to identify similaritiesand differences between the products. Even a product family that performs similar functions does not often have the sameor identical architecture design. In this case, it is difficult to understand the overall relationship by using only each product's DSM. To address this issue, Rojas and Kim [3, 8] proposed a functional matching method that utilizes FCMs to find a set of components involved in performing similar functions for each product variant automatically.

3.2.3 Security Matrix (SecM) The FCM mentioned above can also be deployed to find a set of components related to sensitive (or critical) functions. Rojas and Kim [3] proposed using FCM to automatically find a security matrix (SecM), which means the set of sensitive components related to critical functions (CrFun). The critical function (CrFun) used in this study refers to the function that contains important information and technologies related to the IP of the product. It is assumed that the designers are at the redesign stage for their product family and can easily identify CrFun. CrFun is expressed as a 0 or 1 binary number, the value of 1 indicating that its corresponding function is critical. Figure 3 shows how to find SecM based on FCM and CrFun. Functions 1 through 3 are critical functions and the components $\mathrm{A}, \mathrm{B}$, and $\mathrm{C}$ which are associated with these functions are expressed as 1 in the security matrix. This information is used in the next phase of product architecture optimization for individual products.

\begin{tabular}{|c|c|c|c|c|c|c|}
\cline { 2 - 8 } \multicolumn{1}{c|}{} & CrFun & A & B & C & D & E \\
\hline Func on 1 & 1 & 1 & & 1 & & \\
\hline Func on 2 & 1 & 1 & 1 & & & \\
\hline Func on 3 & 1 & & & 1 & & \\
\hline Func on 4 & 0 & & & & & 1 \\
\hline Func on 5 & 0 & & & & 1 & 1 \\
\hline SecM & & 1 & 1 & 1 & 0 & 0 \\
\hline
\end{tabular}

FIGURE 3. Example of security matrix (SecM) 
To cite as: Kim, J, Saidani, M, \& Kim, HM. "Optimal Product Family Architecture Design and Commonality Decision for Sustainability and Intellectual Property Protection." Proceedings of the ASME 2020 International Design Engineering Technical Conferences and Computers and Information in Engineering Conference. Volume 11B: 46th Design Automation Conference (DAC). Virtual, Online. August 17-19, 2020. V11BT11A034. ASME. https://doi.org/10.1115/DETC2020-22488

\subsection{Phase I: Individual Architecture Optimization}

Based on the data analyzed in the previous phase, the archi-

tecture optimization of individual products is carried out at this stage. The basic product architecture design aims to maximize internal interconnections within the module while minimizing outer interconnections between modules [21]. In this study, the

product architecture of individual products is designed to achieve the objective of the existing architecture design while minimizing the additional penalty costs associated with the IP and easiness of sharing.

3.3.1 Basic Coordination Cost An objective function, basic coordination cost, is to maximize interconnection within a module while minimizing external interconnection between modules [22]. The coordination cost is calculated using the DSMs and the cluster matrix that defines which elements are in each cluster. The coordination cost consists of internal cluster cost and external cluster cost. Equation 5 shows the coordination cost. The IntraCluster is calculated for interaction between components $j$ and $k$ generated within the module. On the other hand, for interaction between components $j$ and $k$ occurring outside of any clusters, the ExtraCluster is calculated. The coordination cost is calculated from the sum of all IntraCluster and ExtraCluster costs.

$$
\begin{aligned}
& \text { IntraCluster } \left.=(\operatorname{DSM}(j, k)+\operatorname{DSM}(k, j)) \times \text { Clustersize }_{(y)}\right)^{\text {power }} \\
& \text { ExtraCluster }=(\operatorname{DSM}(j, k)+\operatorname{DSM}(k, j)) \times \operatorname{DSMsize}^{\text {power }} \\
& \text { Coordcost }=\sum \text { IntraCluster }+\sum \text { ExtraCluster }
\end{aligned}
$$

where $\operatorname{DSM}(j, k)$ is the interaction between component $j$ and $k$. Clustersize $(y)$ is the number of components in the cluster $y$. DSMsize is the number of elements in the DSM. The parameter power represents the penalty factor for the size of clusters.

3.3.2 IP Related Penalty Cost To ensure IP protec- tion, this study uses the concept of IP modularity integratedinto product design. The IP modularity refers to the component boundary in different IP status that corresponds to the technical boundary of module [4]. Rojas and Kim [3] also suggested the concept of restricted modules for constraints that a set of compo-

nents in the security matrix cannot be distributed to other modules and exist within one module. The method proposed by Rojas and Kim [3] is applied for the penalty cost that reflects IP mod-

ularity. For this constraint, the number of mismatches between their clustering solution and security matrix is calculated through

$P_{s}$ as shown in Eq. 6.

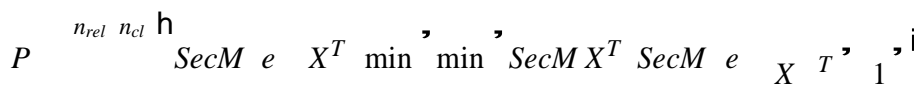

$$
\begin{aligned}
& \begin{aligned}
s= & \sum_{i=1} \sum_{j=1} i(-j) \quad i j, \quad i(-j), \\
& +\sum_{i=1}^{n_{\text {rel }} \mathrm{h}} \operatorname{SecM}_{i} e^{T}\left(1-\min { }^{T} \operatorname{Sec}_{i} X_{j}^{T}, 1, \mathbf{i}\right.
\end{aligned}
\end{aligned}
$$

where $X_{j}$ is the $j^{\text {th }}$ row vector of clustering matrix $(X)$, and $e$ is a unity row vector of the appropriate dimension. $n_{c}$ is the number of components. $n_{r c l}$ is the number of restricted set, and $n_{c l}$ is the cluster number.

$$
\text { Penaltycost }=P_{s}\left(n_{c}+n_{r c l}+n_{c l}\right)
$$

The penalty cost is calculated by multiplying this mismatches $\left(P_{s}\right)$ by the description length $\left(n_{c}+n_{r c l}+n_{c l}\right)$ as defined in Eq. 7 , since the description of this mismatch would be given by the number of components, restricted sets, and clusters.

3.3.3 Design for Easy Sharing When designing the architecture of a product family that includes IP-related parts, designers should choose a design with a low risk of the redesign. The reason is that it will require more time and cost if more parts need to be changed to redesign existing designs. Therefore, it is necessary for the solution generated in the next stage to be reflected in the individual product architecture so that the shared candidates can be easily shared.

To do so, a metric proposed by Rojas and Esterman [23] is applied to measure the ease of changing components in a given architecture. The Cost Impact Metric $\left(\mathrm{CIM}_{j}^{k}\right)$ of component $j$ in product $k$ is calculated by multiplying the $\mathrm{MDL}^{k}$ and $\mathrm{CI}^{k}$, whose

the detailed descriptions and formulas are as follows: $\mathrm{MDL}_{j}^{k}$ represents the number of links from the component $j$ in product $k$ which measures how strongly the component $j$ is connected to other parts [24]. $\mathrm{CI}_{j}^{k}$ is the Coupling Index (CI) of component $j$ in product $k$ which represents the impact of a change in the specifications of the components [25]. The effect of a component specification include both the repercussions of changes in that component on other components (CIS) and the effects of other components (CIR).

$$
\mathrm{CIM}^{k}=\mathrm{MDL}^{k} \mathrm{CI}^{k}
$$

$$
\begin{aligned}
& \begin{array}{c}
j \\
\mathrm{MDL}^{k} \\
j
\end{array} \\
& \mathrm{CI}^{k}=\mathrm{CIS}^{k}+\mathrm{CIR}^{k}=\sum^{\frac{k}{c}} \operatorname{DSM}^{k}(i, j)+\sum^{\frac{k}{c}} \operatorname{DSM}^{k}(j, i) \\
& j \quad j \quad j \quad i=1 \quad i=1
\end{aligned}
$$


where $N_{j}^{(u)}$ is the number of components connected to component $j$, and $N^{(u)}$ is the number of components at the level in which the component $j$ is. $c, o$ repreqsent\}components and interfaces, respectively.

The penalty cost for easiness of sharing is calculated as Eq. 9 [3]. This penalty cost readjusts the individual architecture design in a form that makes it easier to share the candidates that are subsequently determined.

$$
\text { Sharingcost }=B_{1} Y_{c}^{k} \mathrm{CIM}^{k}+b_{2} Y_{m}^{k} \mathrm{CIM}^{k}
$$

where $Y$ is the decision vector representing the suitable and sustainable candidates derived through phase II. $Y_{c}$ excludes all components within the security matrix from $Y . Y_{m}$ represents a module that contains the restricted modules among the modules designated as shared candidates under $Y . B_{1}$ and $B_{2}$ are weighting factors.

3.3.4 Total Coordination Cost To integrate these objective functions, the total coordination cost is redefined as Eq.10 The basic coordination cost, IP-related penalty cost, and sharing cost are simply combined through the weighted average method.

$$
\min f=\nu_{1} \text { Coordcost }+\nu_{2} \text { Penaltycost }+\nu_{3} \text { Sharingcost }(10)
$$

where $\gamma_{1}, \gamma_{2}$, and $\gamma_{3}$ are weighting factors.

\subsection{Phase II: Selection of Shared Candidates}

After optimizing the individual product architecture design, the next phase is to select candidates that can be shared between products within a product family. Based on the architectural design of the individual products in the first phase, this phase aims to select suitable and sustainable shared candidates (components and/or modules) between products.

When selecting the candidates to be shared, one needs to consider not only the cost of the redesign that may occur dur- ing the sharing but also the potential value of the shared components for possible future reuse. It is important to select the shared candidates with a high potential residual value at the endof-life (EoL) stage because commonality can lead to economic

and environmental savings when recovering EoL components.

Unlike previous studies that considered only the redesign costs for sharing [3, 8], the Cost Impact Metric (CIM) and the Benefit Impact Metric (BIM) are applied simultaneously. The shared component selection algorithm calculates for all the components the CIM (Eq. 8), which reflects the risk of the redesign that can occur when shared, and the BIM, which reflects the benefits that might arise from sharing. The BIM is indicated by a score of the integer value from 1 to 9 , and components with a high residual value are rated at 9 and those with a low residual value at 1 point.

$$
\begin{aligned}
\mathrm{IM}^{k}= & \frac{\mathrm{CIM}^{k}}{\mathrm{BIM}_{j}^{k}}
\end{aligned}
$$

The Impact Metric $\left(\mathrm{IM}_{j}^{k}\right)$ is obtained by dividing $\mathrm{CIM}_{j}^{k}$ into $\mathrm{BIM}_{j}^{k}$ and normalizing it to a value of $0-1$, according to Eq. 11. After obtaining the IM value of each part, this algorithm performs a functional matching to find suitable and sustainable shared candidates with IM below $\vartheta$. $\vartheta$ is the criterion for determining the shared candidates, the parts and/or modules with the IM value of less than $\vartheta$ are considered to be appropriate shared candidates.

The pairwise comparisons for products are performed after the functional matching process finds the set components for a particular function. In both products, if the sum of the IM of the components associated with that function is less than $\vartheta$, those parts are set as shared candidates $(Y)$ for both products.

\subsection{Phase III: Checking the Environmental Impact Saving}

The commonality is one of the new attributes of the product family that can lead to economies of scale that will affect positively the environmental impact saving [9]. In addition to reducing the cost of repairing or recycling parts, the commonality ensures that enough parts are available for product recovery. This phase identifies the environmental impact saving that could occur if components are shared among products, according to Eq. 12. Different environmental indicators such as global warming potential, ozone depletion, human toxicity, and ecotoxicity can be used to compute the EP parameter (see below), and the environmental impact saving target $(\delta)$ depends on what indicator is used. If the target of environmental impact saving $(\delta)$ is not satisfied, the criterion for determining the degree of commonality $(\vartheta)$ increases in the next step.

$$
\sum_{k j} \sum_{j} \operatorname{EP}^{k} Y^{k} \text { sales }^{k} \geq \delta
$$

where $\mathrm{EP}_{j}^{k}$ denotes the environmental impact saving of $j$ component in product $k$. $\delta$ represents the target of environmental impact saving. sales ${ }^{k}$ denotes the expected sales volume of a product $k$. 
To cite as: Kim, J, Saidani, M, \& Kim, HM. "Optimal Product Family Architecture Design and Commonality Decision for Sustainability and Intellectual Property Protection." Proceedings of the ASME 2020 International Design Engineering Technical Conferences and Computers and Information in Engineering Conference. Volume 11B: 46th Design Automation Conference (DAC). Virtual, Online. August 17-19, 2020. V11BT11A034. ASME. https://doi.org/10.1115/DETC2020-22488

The process is repeated until the change in the decision vectors $(Y)$ for all the products being considered is below a given tolerance $\varepsilon$ :

$$
\sum_{k=1}^{m}\left\|Y^{k}(t)-Y^{k}(t-1)\right\|^{2} \leq \varepsilon
$$

\section{ILLUSTRATIVE CASE STUDY: APPLICATION TO A PRINTER-PRODUCT FAMILY}

To demonstrate and test the new methodology developed in this paper, an illustrative case study is conducting on (re)designing printers in the context of product family with both security and sustainability considerations. Printers are an example of products that use design strategies for IP protection to prevent the recycling of products to sell parts that require replacement and to prevent their designs from leaking to other companies. For example, HP uses different printhead components between product variants, even though the printhead is a general functional component that does not give customers any additional satisfaction [5]. The reason for not generalizing print heads is to prevent third parties from increasing competitiveness in the printer and replacement parts markets due to lower recovery costs.

The proposed methodology is applied to redesign printers. In this study, two printers from the same OEM (hereafter, printer model I and printer model II) are analyzed to identify their product architecture and shared component candidates to improve their sustainability while protecting their security.

\subsection{Printers Architecture Analysis}

The interface DSMs, FCMs, and CrFun of printers developed in the previous study were applied [3]. In this study, in addition to interface DSMs, both lifecycle and material-based DSMs were deployed to identifying further potential clusters of similar components in terms of lifetime and materials compatibility, facilitating thus their sustainable maintenance and management. The sustainability-related DSMs were built based on the printer case study [26] and incorporating materials compatibility and recyclability elements according to the estimated bill of materials, available in Appendix A. These DSMs and FCMs are not provided in this paper due to space limitations but are available on demand.

\subsection{Printers Architecture Design}

The individual product architecture design algorithm was performed based on the DSM algorithms developed by Thebeau [22]. The total coordination cost includes the structure of modular models, penalty costs for security, and ease of sharing. The objective function of the algorithm for the design of individual

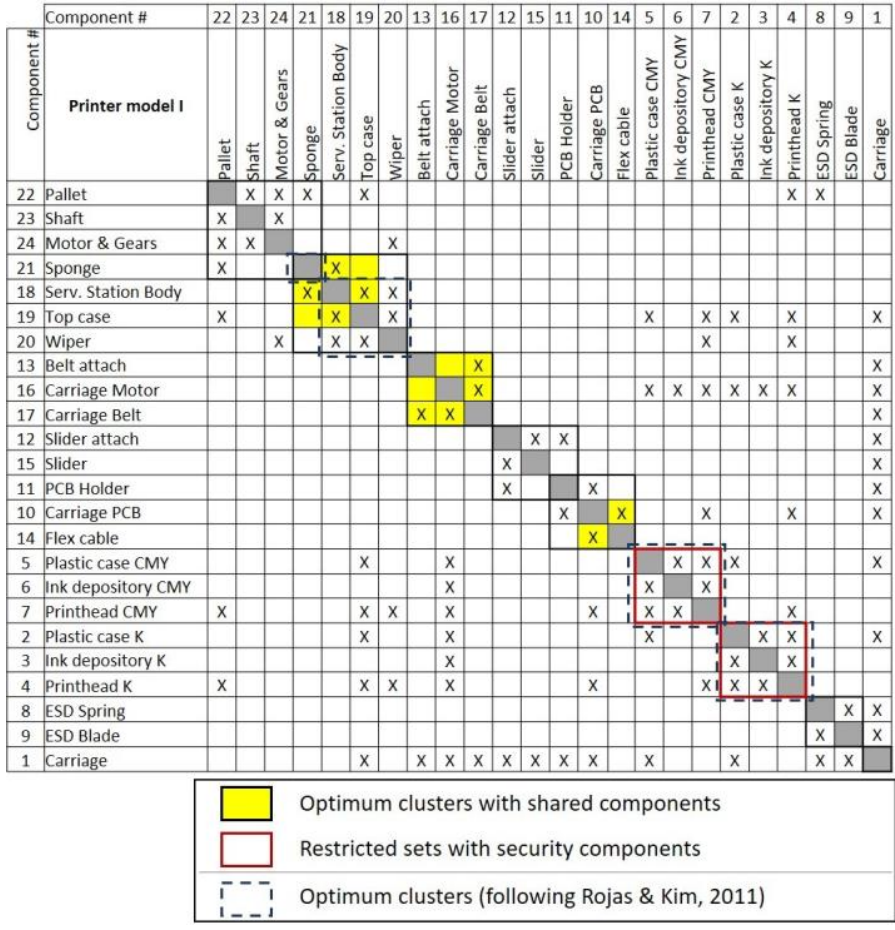

FIGURE 4. Optimum clusters for the printer model I

product architectures is the one defined in Eq. 10. The results of the architecture design of the printer model I and printer model II are shown in Fig. 4 and 5, respectively. The results of the product architecture design confirmed that security-related components were within one module through IP modularity. Also, most of the shared candidates consisted of easy-to-share forms within a module, rather than individual components.

\subsection{Selection of Shared Candidates}

The results of the selection of shared candidates between the printer model I and printer model II are shown in Tab. 1. Table 1 also shows the results of Rojas and Kim [3], which only considers security. Comparing the two results, components and modules with more potential value were selected as shared candidates when both sustainability and security were taken into account, rather than only security. The shared candidate sets between the two printers were those that were not related to critical functions and restricted module sets. Also, the candidates were potentially valuable components (i.e., composed of parts made of materials of high value for recycling, such as aluminum and copper) for recycling and reuse rather than just the sponge.

\subsection{Checking the Environmental Impact Saving}

The SimaPro software (version 8.5) [27] was used to model the product systems and to perform the environmental impact as- 
To cite as: Kim, J, Saidani, M, \& Kim, HM. "Optimal Product Family Architecture Design and Commonality Decision for Sustainability and Intellectual Property Protection." Proceedings of the ASME 2020 International Design Engineering Technical Conferences and Computers and Information in Engineering Conference. Volume 11B: 46th Design Automation Conference (DAC). Virtual, Online. August 17-19, 2020. V11BT11A034. ASME. https://doi.org/10.1115/DETC2020-22488

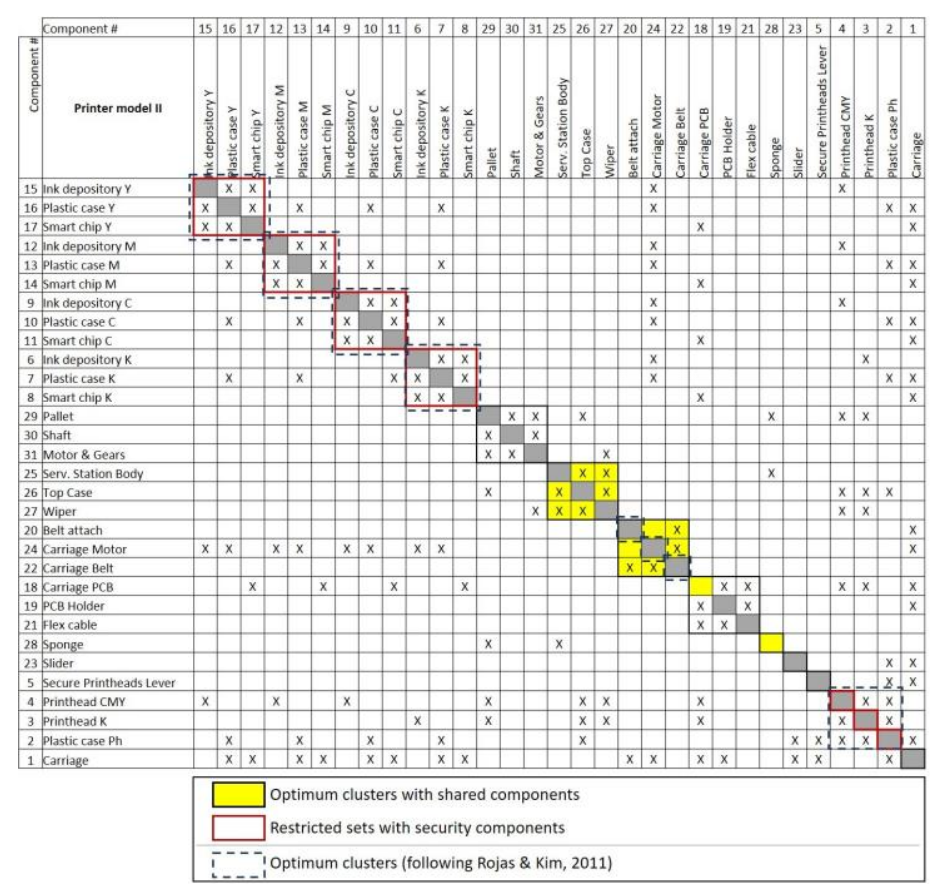

FIGURE 5. Optimum clusters for the printer model II

sessment. Within SimaPro 8.5, the ecoinvent database (version 3.4) [28], and the ReCiPe Midpoint/Endpoint (H) methodology [29] have been used to conduct the environmental evaluation according to the life cycle assessment ISO standard (14040:2006). Particularly, in the present study, the indicator of climate change (global warming potential, GWP100a) is used to quantify/assess the carbon footprint associated with each potential module and associated components. For reference, the GWP100a is an indicator of how much heat is trapped in the atmosphere over a period of 100 years by greenhouse gases emitted by human-made activities. The GWP100a impact is expressed in terms of kilograms of carbon dioxide equivalent ( $\mathrm{kg}$ of $\mathrm{CO}_{2}$ eq.). The environmental impact includes the impact generated from the manufacture of the printer parts (processing of the components), as well as the impact from the extraction and production of all its constituent

\begin{tabular}{l|l}
\hline & Selected shared components \\
\hline & $\begin{array}{l}\text { Carriage PCB, Belt attach, Flex cable } \\
\text { Carriage motor, Carriage belt } \\
\text { Proposed method } \\
\text { (Security + Sustainability) }\end{array}$ \\
$\begin{array}{l}\text { Serv. station body, Top case } \\
\text { Sponge }\end{array}$ \\
\hline $\begin{array}{l}\text { Rojas and Kim (2011) } \\
\text { (Security only) }\end{array}$ & Sponge \\
\hline
\end{tabular}

TABLE 1. Comparison of the results for shared candidates raw materials. Manufacturing processes are approximated using industry average processes for metal processing, and injection molding for plastic parts.

The target of environmental impact may vary depending on the nature of the product or the company's strategies and associated commitment to achieve sustainability-related goals. In this illustrative case study, the target value of total environmental impact saving $(\delta)$ was assumed to be the amount of carbon dioxide kilograms to be saved in the production process, which was estimated to be 40,000 ( $\mathrm{kg}$ of $\mathrm{CO}_{2}$ eq.). The estimated number of sales for each printer model was assumed to be 10,000 units each. The initial $\vartheta$ value was set to 0.1 , and the final $\vartheta$ value satisfied the target of environmental impact saving was 0.5 . The final environmental impact saving is 48,500 ( $\mathrm{kg}$ of $\mathrm{CO}_{2}$ eq.).

\section{CONCLUSION AND FUTURE WORK}

The methodology developed in this paper, combining matrix-based tools with a new optimization algorithm, contributes to identifying optimal sustainable product family architecture design while protecting the security of IP-related parts. The methodology particularly enables the selection of shared candidates based on product architecture design. It aims to present product architecture design alternatives to companies that need to establish a sustainable design strategy for the environment while protecting their sensitive design and technology. The main contribution of this study is that security and sustainability, which are rarely considered concurrently in previous studies, are here incorporated together in the product family architecture design and commonality decision.

A case study on a printer-product family is used to experiment and demonstrate the new methodology developed in this paper. This example is a first good illustration of how sustainability can be considered while keeping the security components in product family design. The initial findings validate the usefulness of the framework for designing product structures and selecting components in consideration of sustainability while meeting design constraints for sensitive elements. The results of the individual product architecture showed that the IP modularity was satisfied by encapsulating all the components contained in the restricted sets in the same module. Other components were modularized, considering the relationship between components, material, and life compatibility. Besides, the comparison between the present findings and the previous study [3] which considered only security, the proposed methodology for both sustainability and security selected that more parts and modules with higher potential values as shared candidates.

The proposed methodology can be used as a decision support tool to help product designers identify appropriate product family architecture design and find commonality candidates within a product family by considering sustainability and security. This study uses printers as an example of application but 
can be applied to various system analyses and designs, including security-critical military equipment, or industries that are designing high value and technological products such as the aeronautic or spatial industries.

Future research can be oriented towards the application of various factors affecting commonality decisions. Currently, the difficulty of redesigning and the benefit of sharing in determining commonality are applied, but performance differentiation can be considered by applying a demand model for sharing component decisions. Furthermore, design for intellectual property in a context of remanufacturing or circular economy (e.g., closing-theloop of product family through remanufacturing, reuse, or recycling, while preserving IP) is a promising line of future research to be explored to achieve more economic and environmental savings. Last but not least, to avoid negative impact transfers when redesigning product systems to mitigate the emissions of carbon dioxide (global warming potential indicator), complementary sustainability and circularity indicators have to be integrated and computed in future work [30].

\section{ACKNOWLEDGMENT}

The authors acknowledge Alvaro Rojas for providing the data for the printer case study.

\section{REFERENCES}

[1] Gowers, A., 2006. Gowers review of intellectual property. The Stationery Office.

[2] Krystofik, M., Wagner, J., and Gaustad, G., 2015. "Leveraging intellectual property rights to encourage green product design and remanufacturing for sustainable waste management". Resources, Conservation and Recycling, 97, pp. 44-54.

[3] Rojas Arciniegas, A. J., and Kim, H. M., 2012. "Incorporating security considerations into optimal product architecture and component sharing decision in product family design". Engineering Optimization, 44(1), pp. 55-74.

[4] Henkel, J., Baldwin, C. Y., and Shih, W., 2013. "Ip modularity: Profiting from innovation by aligning product architecture with intellectual property". California management review, 55(4), pp. 65-82.

[5] Subramanian, R., Ferguson, M. E., and Beril Toktay, L., 2013. "Remanufacturing and the component commonality decision". Production and Operations Management, 22(1), pp. 36-53.

[6] Fixson, S. K., 2005. "Product architecture assessment: a tool to link product, process, and supply chain design decisions". Journal of operations management, 23(3-4), pp. 345-369.

[7] Kim, S., and Moon, S. K., 2019. "Eco-modular product architecture identification and assessment for product recov- ery". Journal of Intelligent Manufacturing, 30(1), pp. 383403.

[8] Rojas Arciniegas, A. J., and Kim, H. M., 2011. "Optimal component sharing in a product family by simultaneous consideration of minimum description length and impact metric". Engineering Optimization, 43(2), pp. 175-192.

[9] Yang, Q., Yu, S., and Jiang, D., 2014. “A modular method of developing an eco-product family considering the reusability and recyclability of customer products". Journal of cleaner production, 64, pp. 254-265.

[10] Yang, D., Li, J., Wang, B., and Jia, Y.-J., 2020. "Modulebased product configuration decisions considering both economical and carbon emission-related environmental factors". Sustainability, 12(3), p. 1145.

[11] O'Hearn, P., Yang, H., and Reynolds, J., 2009. "On the criteria to be used in decomposing systems into modules". ACM Transactions on Programming Languages and Systems, 31(3), pp. 1-50.

[12] Simpson, T. W., 2004. "Product platform design and customization: Status and promise". Ai Edam, 18(1), pp. 3-20.

[13] Hölttä-Otto, K., Otto, K. N., and Simpson, T. W., 2014. "Defining modules for platforms: An overview of the architecting process". In Advances in product family and product platform design. Springer, pp. 323-341.

[14] Ma, J., and Kremer, G. E. O., 2015. "A modular product design method to improve product social sustainability performance". In ASME 2015 International Design Engineering Technical Conferences and Computers and Information in Engineering Conference, American Society of Mechanical Engineers Digital Collection.

[15] Kim, S., and Moon, S. K., 2017. "Sustainable plat- form identification for product family design". Journal of cleaner production, 143, pp. 567-581.

[16] Aydin, R., Kwong, C., and Ji, P., 2015. "A novel methodology for simultaneous consideration of remanufactured and new products in product line design". International Journal of Production Economics, 169, pp. 127-140.

[17] Kwak, M., 2018. "Optimal line design of new and remanufactured products: A model for maximum profit and market share with environmental consideration". Sustainability, 10(11), p. 4283.

[18] Alizon, F., Shooter, S. B., and Thevenot, H. J., 2006. "Design structure matrix flow for improving identification and specification of modules". In ASME 2006 International Design Engineering Technical Conferences and Computers and Information in Engineering Conference, American Society of Mechanical Engineers Digital Collection, pp. 399411.

[19] Reuter, M., Hudson, C., Van Schaik, A., Heiskanen, K., Meskers, C., Hagelüken, C., et al., 2013. "Metal recycling: Opportunities, limits, infrastructure". A report of the work- 


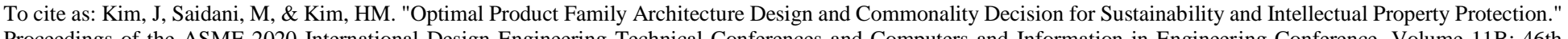

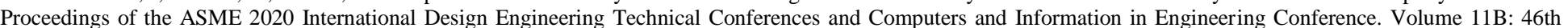
Design Automation Conference (DAC). Virtual, Online. August 17-19, 2020. V11BT11A034. ASME. https://doi.org/10.1115/DETC2020-22488

ing group on the global metal flows to the international resource panel.

[20] Strawbridge, Z., McAdams, D. A., and Stone, R. B., 2002.

"A computational approach to conceptual design". In ASME 2002 International Design Engineering Technical Conferences and Computers and Information in Engineering Conference, American Society of Mechanical Engineers Digital Collection, pp. 15-25.

[21] Ulrich, K., 1995. "The role of product architecture in the manufacturing firm". Research policy, 24(3), pp. 419-440.

[22] Thebeau, R. E., 2001. "Knowledge management of system interfaces and interactions from product development processes". PhD thesis, Massachusetts Institute of Technology.

[23] Rojas, A. J., and Esterman, M., 2008. "A measure of impact for platform changes". In ASME 2008 International Design Engineering Technical Conferences and Computers and Information in Engineering Conference, American Society of Mechanical Engineers Digital Collection, pp. 323-332.

[24] Wang, B., and Antonsson, E. K., 2004. "Information measure for modularity in engineering design". In ASME 2004 International Design Engineering Technical Confer- ences and Computers and Information in Engineering Conference, American Society of Mechanical Engineers Digital Collection, pp. 449-458.

[25] Martin, M. V., and Ishii, K., 2002. "Design for variety: developing standardized and modularized product platform architectures". Research in engineering design, 13(4), pp. 213-235.

[26] Pollock, D., and Coulon, R., 1996. "Life cycle assessment: of an inkjet print cartridge". In Proceedings of the 1996 IEEE International Symposium on Electronics and the Environment. ISEE-1996, IEEE, pp. 154-160.

[27] Pre-sustainability, 2018. SimaPro 8. Available online: https://www.pre-sustainability.com/simapro.

[28] Centre, T. E., 2018. Ecoinvent. Available online: https: //www.ecoinvent.org/database/database.html.

[29] Goedkoop, M., Heijungs, R., Huijbregts, M., De Schryver, A., Struijs, J., Van Zelm, R., et al., 2009. "A life cycle impact assessment method which comprises harmonised category indicators at the midpoint and the endpoint level". The Hague, Ministry of VROM. ReCiPe.

[30] Saidani, M., Kim, H., Yannou, B., Leroy, Y., and Cluzel, F., 2019. "Framing product circularity performance for optimized green profit". In ASME 2019 International Design Engineering Technical Conferences and Computers and Information in Engineering Conference, American Society of Mechanical Engineers Digital Collection.

\section{Appendix: Bill of materials (estimation) for printer model I}

\begin{tabular}{lll}
\hline Component & Material & Mass (g) \\
\hline Plas c case K & Polystyrene (HIPS) & 100 \\
Ink depository K & PET/Polystyrene (HIPS) & $20 / 20$ \\
Printhead K & Polystyrene (HIPS) & 100 \\
Plas c case CMY & Polystyrene (HIPS) & 100 \\
Ink depository CMY & PET/Polystyrene (HIPS) & $20 / 20$ \\
Printhead CMY & Polystyrene (HIPS) & 100 \\
ESD Spring & Steel & 10 \\
ESD Blade & Steel & 20 \\
Carriage PCB & Copper/Epoxy/Glass ber & $70(10 / 30 / 30)$ \\
PCB Holder & ABS & 50 \\
Slider a ach & Aluminium & 10 \\
Belt a ach & Aluminium & 10 \\
Flex cable & PVC/Copper & $25 / 25$ \\
Slider & Aluminium & 70 \\
Carriage Motor & Steel/Copper & $200 / 50$ \\
Carriage Belt & Nylon & 30 \\
Serv. Sta on Body & Steel & 100 \\
Top Case & Steel & 100 \\
Wiper & PVC & 10 \\
Sponge & Polyurethane & 20 \\
Pallet & PVC & 10 \\
Sha & Aluminium & 20 \\
Motor \& Gears & Steel/Copper & $200 / 50$ \\
\hline & &
\end{tabular}

